\title{
JOURNAL
}

of Health Inequalities

\section{Comparing intact and non-intact families in terms of trends in adolescent weekly tobacco smoking and alcohol drinking (Poland: 2002-2014)}

\author{
Joanna Mazur ${ }^{1}$, Anna Kowalewska², Anna Dzielska \\ 'Department of Child and Adolescent Health, Institute of Mother and Child, Warsaw, Poland \\ ${ }^{2}$ Department of Biomedical Aspects of Development and Sexology, Faculty of Education, University of Warsaw, Poland
}

\begin{abstract}
Introduction: Young people who have experienced change in the family situation tend to have more cognitive, emotional and behavioural problems than those from intact families. The aim of the study is to compare adolescents raised with both biological parents and in other families in terms of tobacco smoking and alcohol drinking.

Material and methods: The data come from four rounds of the HBSC (Health Behaviour in School-aged Children) survey conducted in Poland in 2002-2014. The combined sample included 14029 students of the first and the third grade of lower secondary schools. As the main outcome measures, weekly tobacco smoking and weekly alcohol (beer, wine or vodka) drinking were analysed. Multivariate logistic regression adjusted for age and gender was applied to test the significance of change between each two consecutive rounds of HBSC, separately for two types of families.

Results: The percentage of lower secondary school students from intact families decreased from $85.7 \%$ in 2002 to $75.6 \%$ in 2014 . The percentage of students who smoked every week fell from $15.6 \%$ to $11.1 \%$, and the percentage of those who drink any alcohol fell from $9.9 \%$ to $6.6 \%$. In all four rounds of the HBSC, a significantly lower percentage of smokers was noted in adolescents living with both biological parents as compared to non-intact families. In relation to alcohol drinking, significant differences were found in the 2010 and 2014 surveys.

Conclusions: Adolescents from non-intact families are at higher risk of tobacco smoking and alcohol drinking. There is a need to strengthen public health interventions oriented at this type of families.
\end{abstract}

KEY WORDS: tobacco smoking, alcohol drinking, trends, family structure, HBSC study.

\section{KEY FINDINGS}

1. A quarter of lower secondary school students do not live with both biological parents.

2. Young people raised by both biological parents smoke and drink less frequently.

3. The frequency of smoking and drinking has been systematically falling since 2002 but only in intact families.

4. The differences in frequency of smoking and drinking between adolescents in intact and non-intact families have become greater in recent years, in particular with reference to alcohol.

5. The slower overall rate of change in smoking and drinking prevalence in 2010-2014 coexisted with an increased percentage of stepfamilies and a high rate of job migration.

ADDRESS FOR CORRESPONDENCE: Prof. Joanna Mazur, Department of Child and Adolescent Health, Institute of Mother and Child, 17a Kasprzaka Street, 01-211 Warsaw, Poland, e-mail: joanna.mazur@imid.med.pl 


\section{INTRODUCTION}

The family, school and peer group are considered to be important factors which have an impact on engaging in risky behaviours in adolescence [1]. Numerous researchers point to the combined influence of these three agents and some examples of mediation or moderation effects were presented [2]. The negative impact of peers may be limited by a well-functioning family or a strong motivation to study [3]. The protective effect of the family depends on the quality and strength of family bonds, as well as the rules of parental care [4]. Conversely, a lower level of parent education may play a role in reinforcing negative behavioural patterns among young people. Numerous studies have demonstrated that tobacco smoking is more frequent among smokers' children $[5,6]$.

The family structure should be listed as one of the key social determinants of child and adolescent health [7]. An intensification of risky behaviours is observed in the case of absence of one or both parents. It is even more important considering that the current social, economic and cultural changes alter the image of the modern family and pose new threats. The presence of only one parent (usually the mother) is often associated with lower family socio-economic status [8]. Furthermore, economic migration of the parents raises the affluence but at the same time negatively influences family bonds. There are numerous other non-economic (or indirectly related to material conditions) factors, which may intensify risky behaviours in adolescents raised in less traditional families: increased stress, time limitations of a single parent, and experiencing lower responsibility for the child by the step-parent $[9,10]$. Independently of the configuration of the household members, there is a need to strengthen the family factors which protect young people from reaching for psychoactive substances.

Regularly repeated surveys provide an opportunity to monitor the factors that determine health in early adolescence [11]. The most recent national report from the HBSC (Health Behaviour in School-aged Children) survey focused on social determinants of health [12]. The family structure was one of the three analysed factors, along with the place of residence and family affluence. This study extends previous research $[12,13]$.

The aim of the study was to compare the mid-term trends in smoking and drinking in lower secondary school students raised with both biological parents and in other types of families.

\section{MATERIAL AND METHODS}

The data come from four successive rounds of the HBSC survey conducted in Poland in 2002, 2006, 2010 and 2014. It is limited to the two older age groups included in the HBSC survey: 13- and 15-year-olds. The data relate to a total of 6,721 first grade students and 7,308 third grade students of lower secondary school students from all the provinces (total $N=14,029$ ). The characteristics of the Polish sample by gender, age and year of data collection are shown in Table 1.

Out of a number of questions on smoking and drinking provided in the HBSC protocol, two questions related to engaging in such behaviours every week were selected. Both questions were developed by the HBSC network and have been included as mandatory items in all surveys since 1985/86. The first question measured current smoking and its intensity. Students were asked "How often do you smoke at present?" - and provided with response categories: every day; at least once a week, but not every day; less than once a week; I do not smoke. Those who marked the first two answers were identified as regular smokers. The second question was developed to estimate the total intake of alcohol. Students were asked "At present how often do you drink any alcoholic drinks, such as beer, wine, or spirits? Try to include even those times when you only drink small amounts" with

TABLE 1. Sample characteristics in Polish HBSC (Health Behaviour in School-aged Children) surveys in two older age groups

\begin{tabular}{|c|c|c|c|c|c|}
\hline \multirow[t]{2}{*}{ Survey } & \multirow[t]{2}{*}{ Total } & \multicolumn{2}{|c|}{ Age } & \multirow[t]{2}{*}{ Boys (\%) } & \multirow{2}{*}{$\begin{array}{l}\text { Living with both } \\
\text { parents (\%) }\end{array}$} \\
\hline & & Mean & SD & & \\
\hline \multicolumn{6}{|l|}{13 years } \\
\hline 2002 & 2108 & 13.67 & 0.30 & 51.3 & 86.2 \\
\hline 2006 & 1652 & 13.71 & 0.30 & 48.5 & 83.8 \\
\hline 2010 & 1436 & 13.68 & 0.26 & 47.9 & 79.9 \\
\hline 2014 & 1525 & 13.57 & 0.35 & 50.4 & 76.7 \\
\hline \multicolumn{6}{|l|}{15 years } \\
\hline 2002 & 2127 & 15.68 & 0.30 & 48.0 & 85.2 \\
\hline 2006 & 2287 & 15.72 & 0.30 & 47.7 & 82.3 \\
\hline 2010 & 1410 & 15.68 & 0.27 & 48.6 & 80.6 \\
\hline 2014 & 1484 & 15.57 & 0.35 & 47.2 & 74.4 \\
\hline
\end{tabular}


response categories: every day; every week; every month; rarely; never. Those who marked the first two answers for at least one item concerning beer, wine or vodka were identified as weekly drinkers.

In the analysis of the family structure, the question on the home where the surveyed adolescents live or spend most of the time was applied. The question has been included in the HBSC protocol since 2002, which explains why the three previous rounds of survey (19901998) could not be analysed. Young people living with both biological parents were singled out (nuclear or intact family). The remaining families are not a homogeneous group, and combine: single parents or those supported by other adult relatives, remarriages, informal relationships (cohabitation), institutionalised or substitute care provided by other people who are not biological parents. In the combined HBSC sample from 2002-2014 surveys, $82.1 \%$ of respondents lived with both biological parents. In non-intact families, adolescents living with a single parent prevailed (on average $67 \%$ of non-intact families). The percentage of lower secondary school students living in intact families became lower in successive rounds of the HBSC survey (2002 - 85.7\%; $2006-82.9 \%$; 2010 $-80.3 \% ; 2014-75.6 \%)$. The changes in $2010-2014$ were significantly influenced by an increased number of reconstructed families, coexisting with a much slower increase of single parents. It is difficult to assess how much the above trend in the household instability is affected by parental job migration. Only in 2014 was a separate ques- tion asked. Temporary or permanent absence of at least one parent was reported by $7.1 \%$ of adolescents in intact families and $28.3 \%$ in non-intact families.

\section{RESULTS}

In 2002-2014, the percentage of lower secondary school students who smoked regularly decreased from $15.6 \%$ to $11.1 \%$. At the same time the frequency of drinking any alcoholic beverages decreased from 9.9\% to $6.6 \%$.

In the examined period, gender convergence of smoking was observed. Statistically significant differences between boys and girls were noted only in 2002-2006. In 2010, a larger effect size was recorded ( $p=0.095)$, while in 2014 the percentages of smoking boys and girls clearly became equal $(p=0.801)$. In all the rounds of the survey, more frequent drinking was noted in boys than in girls. Exact data on the trends in smoking and drinking by gender and age can be found in Table 2 and Table 3 .

These tables also show data relating to adolescents from intact as well as other families. In a combined sample from 2002-2014, the percentage of lower secondary school students who smoked regularly was $8.1 \%$ and $13.5 \%$ in those groups respectively $(p<0.001)$. The percentage of young people drinking beer, wine or vodka every week was $5.8 \%$ and $7.9 \%$ respectively $(p<0.001)$. A significant difference for the benefit of adolescents living with both parents was present throughout all the years only with reference to smoking. The reason for the deepening of the differences

TABLE 2. Adolescents who smoke every day or at least once a week (\%) by age, gender and presence of biological parents at home

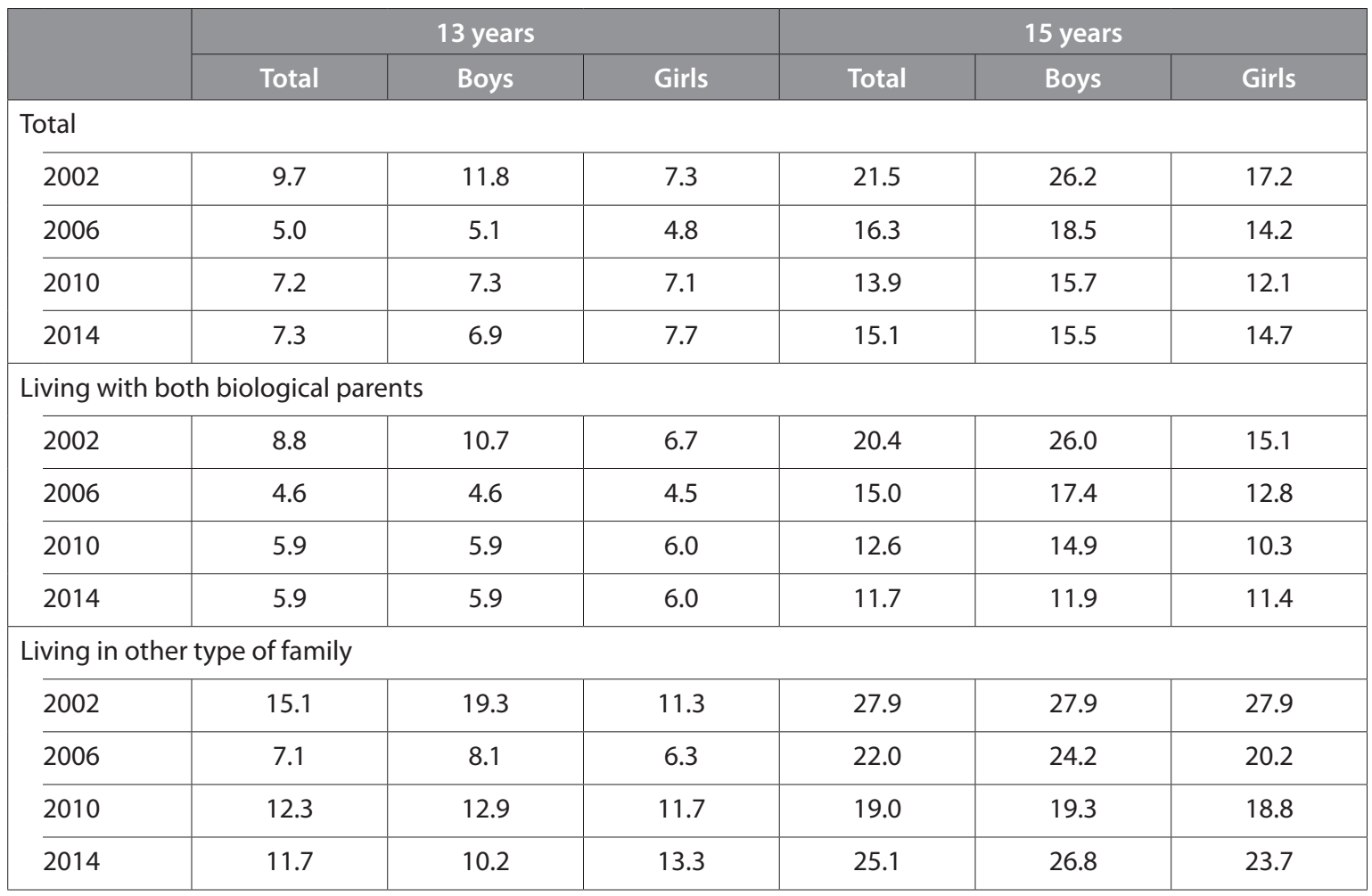


TABLE 3. Adolescents who drink alcohol at least once a week (\%) by age, gender and presence of biological parents at home



in the frequency of drinking since 2010 was a significant downward trend observed only in intact families (Fig. 1).

The statistical evaluation of the changes is shown in Table 4. Data from all pairs of successive years were compared, adjusting for age and gender. The results of the analyses confirmed a downward trend in the frequency of smoking and drinking among young people raised with both biological parents. Moreover, the change increased fast between successive periods. The inference regarding adolescents living with one parent or in a reconstructed family is less optimistic. After an initial period of decreasing frequency of smoking in 2002-2006 and in 2006-2010, a lack of significant changes was found in 2010-2014. With regard to drinking, a significant down-

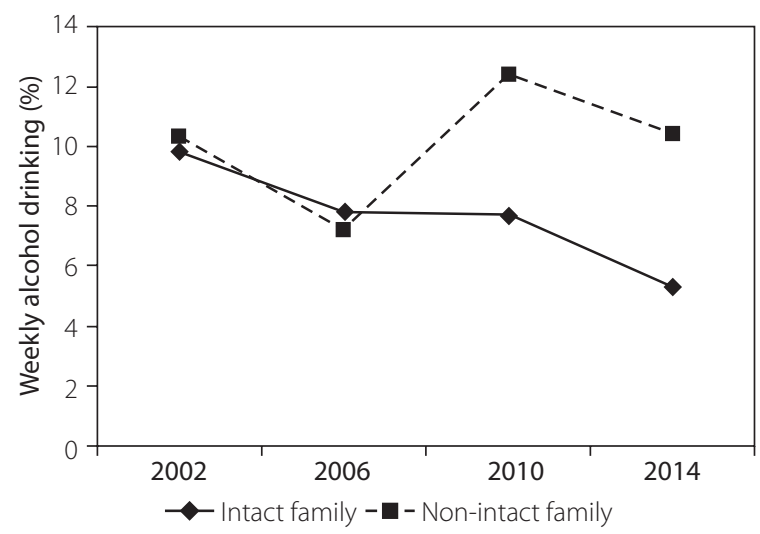

FIG. 1. Adolescents 13 to 15 years old who drink alcohol every week by family type ward change occurred in this group only at the beginning of the investigated period (2002-2006). In 15-year-old boys from incomplete families, an upward trend in the frequency of drinking has been present since 2006 and the percentage noted in 2014 is an all-time high.

\section{DISCUSSION}

The paper presents the mid-term trends in smoking and drinking in lower secondary school students. This is a continuation of previous national [13] and international analyses $[14,15]$ based on the HBSC data. A stratification of trends was performed according to family structure defined by the presence of two biological parents in the household. It was demonstrated that the frequency of smoking and drinking was higher in adolescents living in non-intact families. Furthermore, the pace and the direction of observed changes towards drinking and smoking less were not as positive as in the adolescents living in intact families. Previous studies tried to identify similar trends connected with family affluence [16].

The family structure usually influences the differences in the frequency of psychoactive substance use in simple bi-variate comparisons [17]. Its influence may be less visible after including other social and psychosocial determinants $[17,18]$. Kuntsche and Kuendig [19] indicated the hierarchy of family factors which may have impact on adolescent drinking. Strong bonds in the family (good communication, trust, joint activities) alleviate the consequences of the absence of one of the parents, 
TABLE 4. Significance of change in tobacco and alcohol use estimated for two types of families

\begin{tabular}{|c|c|c|c|c|c|c|}
\hline \multirow[t]{2}{*}{ Survey } & \multicolumn{3}{|c|}{ Living with both biological parents } & \multicolumn{3}{|c|}{ Other type of family } \\
\hline & OR* & $95 \% \mathrm{CI}(\mathrm{OR})$ & $p$ & $\mathrm{OR}^{*}$ & $95 \% \mathrm{Cl}$ & $p$ \\
\hline \multicolumn{7}{|c|}{ Dependent variable: weekly tobacco smoking } \\
\hline 2002 & 1.000 & & & 1.000 & & \\
\hline 2006 & 0.641 & $0.554-0.743$ & 0.000 & 0.636 & $0.478-0.847$ & 0.002 \\
\hline 2010 & 0.591 & $0.498-0.703$ & 0.000 & 0.673 & $0.497-0.912$ & 0.010 \\
\hline 2014 & 0.560 & $0.470-0.666$ & 0.000 & 0.817 & $0.622-1.073$ & 0.147 \\
\hline \multicolumn{7}{|c|}{ Dependent variable: weekly alcohol drinking } \\
\hline 2002 & 1.000 & & & 1.000 & & \\
\hline 2006 & 0.724 & $0.609-0.860$ & 0.000 & 0.636 & $0.427-0.948$ & 0.026 \\
\hline 2010 & 0.759 & $0.625-0.921$ & 0.005 & 1.272 & $0.880-1.841$ & 0.201 \\
\hline 2014 & 0.516 & $0.415-0.641$ & 0.000 & 1.015 & 0.708-1.455 & 0.934 \\
\hline
\end{tabular}

*Multivariate logistic regression model adjusted for age and gender; previous year of data collection as reference category.

reducing the risk of copying the negative behaviour patterns of adults.

A limitation of the above analyses is the inclusion of only two categories of families and a lack of assessment of the impact of other family factors. It is also difficult to evaluate whether the family has been functioning this way for many years (since the respondent's early childhood) or the changes have only occurred recently. In the light of the data from the 2014 Polish HBSC survey, the negative trends in psychoactive substance use among the children of single parents deepen among 15-year-olds and in boys. Boys from this group definitely earlier reach for alcohol and get drunk at a younger age. However, in reconstructed families some risky behaviours intensify at younger age and in girls. A hypothesis can be made that single parent families (mostly mothers) are more influenced by economic factors [12].

The obtained results may be interpreted against the background of selected health promotion theories, in particular the diffusion theory [20]. The pace at which the positive message of health promotion reaches various social groups depends on a number of factors, including the nature of the social system. Society can be divided into five groups: innovators, early adopters, early majority, late majority and laggards. Numerous programmes aimed at preventing risky behaviours may faster reach young people from privileged backgrounds, while their effect is multiplied by a strong family. Adolescents from non-intact families may be over-represented in the last two of the above-mentioned groups. This has serious social implications as the percentage of young people living without at least one parent is constantly increasing and is currently at $25 \%$.

Further analyses should aim towards an extensive assessment of the family environment, the reasons for and the consequences of parental absence. So far, too little attention has been given to the impact of financially motivated migration of the parents on the subjective health and health-related behaviours of adolescents [21]. As for the prevention programmes, emphasis should be put on the strengthening of the protective factors in non-intact families. The goal should be to reverse the negative trends in smoking and drinking among young people from these families [22].

\section{DISCLOSURE}

Authors report no conflict of interest.

\section{References}

1. Shortt AL, Hutchinson DM, Chapman R, et al. Family, school, peer and individual influences on early adolescent alcohol use: first-year impact of the Resilient Families programme. Drug Alcohol Rev 2007; 26: 625-634.

2. Marschall-Lévesque S, Castellanos-Ryan N, Vitaro F, et al. Moderators of the association between peer and target adolescent substance use. Addict Behav 2014; 39: 48-70.

3. Brook JS, Balka E, Zhang C, et al. Adolescent academic adjustment factors and the trajectories of cigarette smoking from adolescence to the mid-thirties. Int J Ment Health 2011; 40: 7-21.

4. Van Ryzin MJ, Fosco GM, Dishion TJ. Family and peer predictors of substance use from early adolescence to early adulthood: an 11-year prospective analysis. Addict Behav 2012; 37: 1314-1324.

5. Mazur J, Tabak I, Małkowska-Szkutnik A. Społeczne uwarunkowania palenia tytoniu przez młodzież w wieku 13-18 lat oraz jej narażenie na bierne palenie $\mathrm{w}$ domu [Social determinants of tobacco smoking in 13-18 year-old adolescents and their exposure to secondhand smoking at home]. Prz Lek 2011; 68: 835-839.

6. Mays D, Gilman SE, Rende R, et al. Parental smoking exposure and adolescent smoking trajectories. Pediatrics 2014; 133: 983-991.

7. Lopoo LM, DeLeire T. Family structure and the economic wellbeing of children in youth and adulthood. Soc Sci Res 2014; 43: 30-44. 
8. Campbell M, Thomson H, Fenton C, et al. Lone parents, health, wellbeing and welfare to work: a systematic review of qualitative studies. BMC Public Health 2016; 16: 188.

9. Griesbach D, Amos A, Currie C. Adolescent smoking and family structure in Europe. Soc Sci Med 2003; 56: 41-52.

10. Barrett AE, Turner RJ. Family structure and substance use problems in adolescence and early adulthood: examining explanations for the relationship. Addiction 2006; 101: 109-120.

11. Schnohr CW, Molcho M, Rasmussen M, et al. Trend analyses in the health behaviour in school-aged children study: methodological considerations and recommendations. Eur J Public Health 2015; 25 (Suppl 2): 7-12.

12. Mazur J (ed.). Zdrowie i zachowania zdrowotne młodzieży szkolnej w Polsce na tle uwarunkowań socjodemograficznych [Health and health behaviour of school-children in Poland in the light of sociodemographic determinants]. Instytut Matki i Dziecka, Warszawa 2014.

13. Mazur J, Dzielska A, Kowalewska A, et al. Current trends in tobacco smoking among 15-year-old adolescents in Poland in the background of 30 countries. Prz Lek 2016; 73: 685-689.

14. Aaro LE, Mazur J, Zatoński WA, et al. Trends in smoking among Polish and Norwegian youth 1986-2014. J Health Inequal 2016; 2: 44-51.

15. de Looze M, Raaijmakers Q, Bogt TT, et al. Decreases in adolescent weekly alcohol use in Europe and North America: evidence from 28 countries from 2002 to 2010. Eur J Public Health 2015; 25 (Suppl 2): 69-72.

16. Mazur J, Woynarowska B. Picie alkoholu przez 15-letnią młodzież w Polsce w latach 2002-2010. Zmiany w ogólnej populacji oraz według płci i zamożności rodziny [Alcohol drinking among 15-year-old Polish adolescents in the years 2002-2010. Nationwide trends and tends by gender and family affluence]. Alkohol Narkom 2011; 24: 275-296.

17. Wojtyniak B, Mazur J (eds.). Społeczne nierówności w zdrowiu dzieci i młodzieży w Polsce w świetle badań populacyjnych [Social inequalities in child and adolescent health in Poland in the light of population studies]. NIZP-PZH, Warszawa 2016.

18. Kowalewska A, Mazur J. Struktura rodziny a inicjacja tytoniowa i regularne palenie przez młodzież w Polsce [Family structure of smoking onset and regular smoking among adolescents in Poland]. Prz Lek 2015; 72: 526-530.

19. Kuntsche EN, Kuendig H. What is worse? A hierarchy of family-related risk factors predicting alcohol use in adolescence. Subst Use Misuse 2006; 41: 71-86.

20. Dearing JW. Improving the state of health programming by using diffusion theory. J Health Commun 2004; 9 (Suppl 1): 21-36.

21. Graham E, Jordan L. Migrant parents and the psychological well-being of left-behind children in Southeast Asia. J Marriage Fam 2011; 73: 763-787.

22. Breivik K, Olweus D, Endresen I. Does the quality of parentchild relationships mediate the increased risk for antisocial behaviour and substance use among adolescents in single-mother and single-father families? J Divorce Remarriage 2009; 50: 400-426.

\section{AUTHORS' CONTRIBUTIONS}

$J M, A K$ and $A D$ collected data and prepared the research concept of the publication. JM analysed data and drafted the article. AK and AD contributed to the discussion and literature review. JM, AK and AD revised the paper and finally approved it. 